\title{
The AXA Group Strategy
}

\author{
by Claude Bebear*
}

Seen from Europe, the insurance and financial services world is likely to turn shortly into huge turmoil of changes, out of which only the best organizations will survive.

We have decided to be one of those. I'll try to explain how we expect to succeed.

\section{A turmoil in insurance and financial services}

In Europe, financial services operators will face dramatic changes in the near future: deregulation, opening of the single market. All these changes will result in tougher competition conditions.

To some extent, this can be said also of the US market.

\subsection{Deregulation}

Deregulation is gaining ground strongly, under the combined pressure of consumers and regulators, and also from the increasing temptation for both bankers and insurers to play on each others' ground.

Its first consequence is to introduce a higher degree of competition between various players, and a reduction of margins for the whole market in the aggregate. One can foresee that there will be a large reshuffling of cards among players in the two or three years to come. Every established position will be severely shaken off. This will make life difficult for bankers and savings institutions as well as for insurers.

The deregulation process has already started both in the United States and in Europe some years ago. It is now developing, and it has produced so far only a very limited part of its potential consequences.

\subsection{The European single market}

The single market will be fully in force by the end of 1992 .

Such market will result in two main consequences:

- first, competition will get harder between European players already established in the market.

* President, AXA MIDI Assurances, Paris. This text summarizes the second Geneva Lecture, given in New York on June 13, 1989, and chaired by John Roberts, Vice Chairman, American International Group. 
The more protected or cartellized markets will be struck more severely. Some others, like Great Britain or France will suffer a little less, because they are already more open and competitive.

But everybody will have to face tougher conditions, in all lines of business.

- second, outsider will be more attracted than before by that new single market.

Large players from North America or Japan, for instance, can only be more interested by a single market of 325 million people, representing $25 \%$ of the worlds' total wealth, than by 12 separate markets, which was the former situation.

So, their strategy will be to reinforce their presence in that market and to build up market shares. And this will result, again, in increased competition.

All these changes can be summarized by just these two single words: increased competition. And this competition will take place inside a market which will be a worldwide one, because all large players will play more and more against each other in all countries throughout the world.

One has to face these new conditions now, and to take steps in order to take advantage from changes, rather than being taken over by them.

\section{Which strategy?}

We, in AXA, have been conscious of such issues maybe earlier than some others, because we were comparatively small by the beginning of the eighties. At that time, AXA was a group of medium-size mutuals, some of them dating back from the beginning of the last century, with a total amount of premiums of just half a billion dollars. Given the changes to come, this was too small to enable the Group to survive in the long term.

\subsection{Size}

So we decided to grow, and size has been, from that time, a basic element of our strategy.

We decided to fuel growth both by internal and external means.

lnternal means: that is profitability, competitivity, innovation. And, as we were mutuals, we had to count only on our own strenghts, when financing our development. And this was a period where we developed a corporate philosophy of quality of service, and excellence, because that was the only choice for us.

External means: we began external growth by building up partnerships with other mutuals, mainly small ones, which could benefit from our experience, financial strength and skills. And this resulted in a group of Mutuals which we called Mutuelles Unies (united mutuals), and which formed the core of the future AXA Group by the beginning of the eighties.

Then, we were fortunate enough to take control of a large quoted company, of very good reputation, Groupe Drouot, which was twice as large as Mutuelles Unies in terms of premiums. This took place in 1982, and resulted in a strengthening of both parties, by way of cross-fertilization between both management teams.

In 1986, we took over another large quoted company, the Presence Group. This resulted in a growth of $50 \%$ in terms of premiums, and again, we took advantage of the mixing of various cultures to enrich the potential of the Group. 
Then, in 1988, we merged our insurance activities with those of Compagnie du Midi, and we took control of that company. After that merger, the total premiums nearly doubled, and amounted some 6.4 billion dollars in 1988 .

Now, is that enough?

Probably not.

We think that in the tough world to come, there will be only two kinds of survivors: niche players, and large players.

We have decided not to be a niche player. And consequently, we will be a large player. But how large?

When we look around us, we can see that we are still comparatively small in "world" terms. We rank approximately No 30 in the world, and No 8 in Europe, and we consider that we are still too much behind what could be called a "world size".

Our target is to rank among the 20 first insurance groups in the world by the end of the century.

We think that such a size is necessary to be in a position to attract the best people, to develop the best information systems, to build up the best spread of risks, to take advantage of opportunities, and to be able to finance all that.

If we watch what European competitors are presently doing, we can see that many of them have followed the route we opened: the 1992 deadline has pushed most of the large European Groups into a strategy of growth, mainly by acquisitions. This conforts us in the belief that we where right by taking decisions in that direction some 10 years ago.

Size is not a target in itself. It is only a condition for survival. It has to be completed by other strategic targets, which are, for AXA: internationalization, professionalism, and decentralization.

\subsection{Internationalization}

Once you choose the size strategy, you have to decide to be present in all large markets, and not only in your own domestic one. Remaining just a domestic insurer makes you too vulnerable to local conditions, economic or legal. So you must develop foreign activities.

In addition, when doing so, one can gain better knowledge of what is going on throughout the world. One can also improve one's efficiency in all fields of the business by developing or acquiring new skills abroad, which can be used in other markets, ahead of competitors.

Internationalization is a source of efficient cross-fertilization.

For the moment, our activities are $2 / 3$ domestics and $1 / 3$ foreign.

Our target is to raise our foreign activities to at least $50 \%$ by the end of the century.

We want to achieve such target by being active on every large market in the world. We started by expanding in European markets, of course, because they are the ones which we know best and which are the closest to us. But we aim to be present also in North America, and particularly in the United States (we are already established in Canada). We have been looking for good opportunities in the States for several years. 
We think also of the Far East as an area where an international insurer has to be present as well.

On every individual market we are working in, our strategy is to be significantly large. Large enough to enable our operations to be self-supporting and to be in a position to attract good people as well as good risks.

\subsection{Professionalism}

- Concentrate on insurance:

As we want to be among the winners in the competition, we believe that this can be achieved only by concentrating on our core business which is insurance.

We don't believe in conglomerates. We don't believe in trying to act in somebody else's profession. This is just underperforming.

If you want to be good, you have to be good in your job, and to try to be better and better in it all the time.

So the corporate philosophy of the Group emphazises that AXA is an insurance Group, and that it concentrates on insurance.

In the same time, we have to face changes in financial markets, as I said previously. There is more and more competition between insurance and other sectors, such as banks, unit trusts, etc.

Consequently, we have to be active also in those markets which overlap with other sectors activities, and not just suffer without reacting. We do it preferably by finding partners, and not by doing things ourselves, because we would not do it as efficiently as a partner.

- Reorganize our French business by channels of distribution:

We have also to take into consideration the changes in clients' attitudes: people want services and not just products, and this implies dramatic changes in our ways of approaching sales and marketing, and of dealing with sales channels.

Because of that, we have decided to rebuild our French organization from bottom to top, in order to deal with theses changes. Basically, our structure relies on three "entities" specialized by channels of distribution.

- the one which deals with exclusive Agents is "AXA Assurances". It is currently being built up and will be fully operational in 1991. It will act through 4200 exclusive Agents, and will be the largest Agents office in France.

- Uni Europe deals only with brokers. It has been launched in March 1988 and is in operation since then.

- Franklin Assurances operates through any other channels. It has just been settled in its new building and has started its operations last year.

When reorganizing our activities in that way, we believe that we will be in a better position to address various clientele segments through those sales channels which are, in each case, most appropriate.

\subsection{Decentralization}

Decentralization has been part of the corporate philosophy from the old times of Mutuelles Unies, because we were, in fact, a group of independent Mutuals. 
It is important that each Company may take decisions by itself, without refering to the federative level. And, at the same time, every Company has to follow a common line of action, which is defined and agreed at the federative level.

So we built up a set of "common management principles", which were a kind of a "Constitution of AXA".

These common principles have been reviewed at every stage of the Group's growth, in order to incorporate new ideas coming from new offices entering the Group, and to be adopted by them.

Among these principles, decentralization and responsibility of managers are essential. And they have grown more crucial again when the Group was gaining size, for decentralization is the only way to manage a large organization efficiently.

For a large office, the only alternative to decentralization is just centralized paralysis.

Decentralization by us means two things:

- first, every organization is totally responsible for its own activities, within the framework of Group guidelines, of course. When we take control of a new organization, we keep the local management in charge. We do not change it, we don't sack people. We do not put a French Chairman or General Manager in charge in our foreign operations. On the contrary, we help the local management already in charge to achieve its corporate objectives and we consider it as fully responsible for its decisions.

- second, inside each office in the Group, every manager at any level of responsibility is given full delegation of authority in his area. This is inside decentralization, within all levels of an organization.

We believe that such philosophy is the one which can enable the best people to give the best of themselves to the organization. It enhances sense of initiative, of decision-making at all levels, and helps us to aim to leadership.

\subsection{Leadership}

In fact, everything described here is just a set of strategic targets and means we are making use of with the purpose of aiming to leadership, in each market where we carry business.

Leadership is a word which summarizes the ultimate target we would like to achieve in AXA, a target that each insurer has certainly in view for his own organization, I am sure, with his own style and in his own environment. 